\title{
Editoriali
}

\section{The experimental method and the problem of psychiatry as a science}

\author{
MICHAEL SHEPHERD
}

No discussion of the experimental method can ignore Claude Bernard's 'Introduction to the Study of Experimental Medicine' (Bernard, 1927). Describing the 'true scientist', Bernard observes:

"The true scientist is one whose work includes both experimental theory and experimental practice. (1) He notes a fact; (2) à propos of this fact, an idea is born in his mind; (3) in the light of this idea, he reasons, devises an experiment, imagines and brings to pass its material conditions; (4) from this experiment, new phenomena result which must be observed, and so on and so forth".

The clarity and force of Bernard's exposition, allied to his scientific achievements, have rendered him a progenitor of what has come to be known as the hypothetico-deductive method, a term often associated with the work of the philosopher Karl Popper (1963), though its roots can be traced back to a much earlier epoch. In Bernard's words:

"A hypothesis is ... the starting point of all experimental reasoning. Without it no investigation would be possible, and one would learn nothing: one could only pile up barren observations. To experiment without a preconceived idea is to wander aimlessly».

Further, as Bernard emphasised, «if one proposes a hypothesis which experience cannot verify, one abandons the experimental method». From this proposition derives the crucial concept of falsification as the primary task of the experimental scientist who sets out to repudiate what is false. The elucidation

Indirizzo per la corrispondenza: Professor M. Shepherd, Prof. Emeritus of Epidemiological Psychiatry, Institute of Psychiatry, University of London, De Crespigny Park, Denmark Hill, London SE5 8AF (England).

Fax $(+44)$ 171-7035796. of this process, of course, says nothing about the source of the idea from which hypotheses emerge as C.S. Peirce's «spontaneous conjectures of instinctive reasoning».

The cornerstone of this whole enterprise is the scientific 'fact'. This simple-seeming notion has been challenged by another distinguished scientist, Ludwik Fleck, in his remarkable monograph, 'The Genesis and Development of a Scientific Fact' (Fleck, 1979). Fleck's thesis, one which has since received widespread support, is illustrated by his detailed discussion of the Wassermann reaction, itself a chance discovery which could not have been appreciated without the prior establishment of the clinical concept of syphilis which had been evolving since the late fifteenth century via astrological signs, the 'carnal scourge' blood dyscrasias and, eventually, infectious disease. With regard to causation, Fleck concludes: «The statement, 'Schaudunn discovered Spirochaeta pallida' is equivocal as it stands, because 'syphilis' as such does not exist. There was only the then-current concept available on the basis of which Schaudunn's contribution occurred». The formulation, therefore, depended on the clinical concept of syphilis and cannot be taken to exemplify Fleck's concept of a scientific fact which he defines as follows: «a thought-stylised conceptual situation which can be investigated from the point of view of history and from that of psychology, both individual and collective, but which cannot be substantively reconstructed in toto simply from these points of view". For Fleck the Wassermann reaction, in effect, served principally to symbolise observational data in the contact of a wider framework of knowledge, namely the historical sociology of scientific thought.

This is a far cry from Alexander Fleming's call for 
'facts, not hot air', but it is consonant with the standpoint of modern medical historians. One of the most distinguished of these, Professor Owsei Temkin, addressed himself to the issue with his customary clarity (Temkin, 1959). Taking Claude Bernard as his starting-point, Temkin points out that this

" ...concept of research ... implicitly accepts a theory of the history of science. It does not matter whether he knows anything about that history. What matters is the conviction that 'true science' corrects the old, discovers the new, thus cannot fail to advance, over the old. Claude Bernard's 'Introduction to Experimental Medicine' formulates a method of scientific research that embodies the assurance of scientific progress. Apart from logical reasoning, he recognised only facts (which can be accumulated), ideas (hypotheses, which are provisional, by definition), and the devising of experiments».

For Temkin the history of all science, pure and applied, represents an interplay between the internal' autonomous view of the practising scientist and the 'external' non-objective factors impinging on it. Claude Bernard, in his view, had developed a picture of science based on hypothesis-testing by experiment which allowed of no assumptions leading to a different outlook on the scientific method. 'To the historian', says Temkin, 'it appears desirable to study ideas, discoveries and inventions as well as institutions and biographical data in relation to their times. Underpinning many of these ideas and discoveries is the emphasis laid by scientists on the acquisition of facts'.

The bearing of the experimental line of reasoning on somatic medicine is apparent. It applies the principles of natural science to physical illness and has been principally responsible for the striking advances made in the past 150 years. The study of psychological medicine, however, introduces another dimension into the field of inquiry. No one has stated the case more cogently than the psychiatrist/philosopher, Karl Jaspers: «Science is wrongly identified with Natural Science ... natural science is indeed the groundwork of psychopathology and an essential element in it but the humanities are equally so and, with this, psychopathology does not become in any way less scientific but scientific in another way (Jaspers, 1962)». And referring specifically to the use of the experimental method in the investigation of such features as psychological performance and function, intelligence, personality and constitution, Jaspers concludes: "We should certainly try experiment where questions can be suitably answered in this way; otherwise we should look out for other methods, such as simple observation and the study of the patient's life-history the use of cases, statistical methods and methods of sociology" (Jaspers, 1962). Here he is underlining the need to recognise the limits of every method of inquiry, experimentation being only one, and to acknowledge the importance of the psychological, social and subjective elements in human behaviour which are not susceptible to investigation by these means.

These generalizations are best related to a specific example. None is more telling than the work of Joseph Goldberger on the elucidation of the mental disorders associated with pellagra. At the turn of the century Goldberger, a clinical epidemiologist with virtually no knowledge of mental disorder, was assigned by the Surgeon General of the United States to investigate this disorder, then an important cause of admission to mental hospitals, especially in Italy and the southern states of the US. The dominant view was that its causation was attributable to an infectious agent, a toxin or possibly a genetically determined form of degeneration. Goldberger approached the matter from a different standpoint and in the first of a remarkable series of papers he recorded his basic hypothesis:

«It is striking ... that although many inmates develop pellagra after varying periods of institutional residence, some even after 10 to 20 years of institutional life and, therefore, it seems permissible to infer, as the result of the operation within the institution of the exciting cause or causes, yet nurses and attendants living under identical conditions appear uniformly to be immune. If pellagra be a communicable disease, why should there be this exemption of the nurses and attendants?» (Goldberger, 1914)

His answer, framed in the form of an hypothesis, was a difference in the diet of the 2 groups of residents and it was extended to account for the extramural association of the disease with rural poverty. To test his assumption Goldberger adopted the hypothetico-deductive model in a four-pronged programme of research designed to demonstrate (1) that there was a difference in the diet of pellagrins and non-pellagrins; (2) that the disease could be cured by a suitable diet; (3) that it could be prevented by such a diet; and (4) that it could be produced experimentally by such a diet. The series of epidemiological experiments which he then undertook remain classical examples of clinical science. Only when the association between pellagra and dietary deficiency had been clinched did he engage 
in laboratory experiments to study the pellagra-preventive action of various foods and to identify the nature of the specific deficiency, using the animal model of canine black-tongue to identify nicotinic acid.

But having demonstrated the biological cause of the pellagra psychosis Goldberger took full account of a host of non-biological factors to explain the ambience of the disease in relation to socio-economic circumstances and individual behaviour. The following passage indicates how widely he cast his net:

«Reference may be made to the group of factors that tend to determine the amount and proportion of family income available for the purchase of food, an example of which is the occurrence of sickness or injury making an unusual draft on the family income.

More tangible than these, and perhaps of more immediate practical importance in its effect on the household diet, is the difference among households with respect to the availability of food supplies. Even granting what is not necessarily the case, that financial ability to provide may be assumed to be invariably synonymous with the actual provision of a good diet and that a liberal diet was actually available to the individual, it by no means follows that such diet was in fact consumed. For such assumption would totally ignore the existence of individual likes and dislikes, more or less marked examples of which may be observed at almost any family table.

Further, a great variety of causes may operate to bring about individual peculiarities of taste with respect to food. They may have their origin in the seemingly inherent human prejudice against the new and untried food or dish; they may date from some disagreeable experience associated with a particular food; they may arise as the result of ill-advised, self-improved or professionally directed dietary restrictions in the treatment of digestive disturbances, kidney disease, etc.; they may originate as a fad; and in the insane they may arise because of some delusions such as the fear of poisoning» (Terris, 1964).
From such considerations Goldberger advanced a multi-factorial concept of pellagra, maintaining that its appearance depended on not only the physical nature of diet but also on dietary habits, individual psychology and the tenant-farm system of cotton production and the availability of certain foods. He concluded: "The situation is manifestly one which calls for study with a view to working out practicable solutions of the economic and agricultural problems. In such study, however, the needs of health must be held in mind as of controlling importance».

This most elegant and conclusive pieces of modern medical research highlights the topic of this editorial. While the experimental method, the centrepiece of much natural science, must play an important part in the scientific study of mental illness it is only one of several approaches that must be employed if a complete picture of the disorder is to be obtained. It is necessary but not sufficient for the task in hand.

\section{REFERENCES}

Bernard C. (1927). An Introduction to the Study of Experimental Medicine (translated by H.C. Greene). Macmillan Co.: New York.

Fleck L. (1979). Genesis and Development of a Scientific Fact. University of Chicago Press: Chicago.

Goldberger J. (1914). The aetiology of pellagra: the significance of certain epidemiological observations with respect thereto. Public Health Reports 29, 1683-1685.

Jaspers K. (1962). General Psychopathology (translated by J. Hoenig and Marian W. Hamilton). Manchester University Press: Manchester.

Popper K.R. (1963). Conjectures and Refutations. Routledge: London.

Temkin O. (1959). Scientific medicine and historical research. Perspectives in Biology and Medicine 3, 70-85.

Terris M. (1964). Goldberger on Pellagra. Louisiana State University: Baton Rouge. 